\title{
REPRESENTACIONES SOBRE EL PROCESO DE INTEGRACIÓN REGIONAL EN LOS DISCURSOS DE LOS LÍDERES POLÍTICOS DEL MERCOSUR
}

\author{
ANDRÉS BUISÁN ${ }^{1}$, PAULA SALERNO \\ Facultad de Filosofía y Letras, Universidad de Buenos Aires \\ buisanandres@gmail.com,paula.ssalerno@gmail.com
}

\begin{abstract}
Resumo. $O$ objetivo deste artigo é questionar as representações de diversos líderes latino-americanos sobre o Mercosul. Para isso, analisa-se um corpus composto por dois encontros específicos: a Reunião Ordinária levada a cabo no dia 17 de dezembro de 2014 na cidade de Paraná, Argentina, no âmbito da $47^{\circ}$ Cúpula de Chefes de Estado do Mercosul, e a Reunião Plenária realizada no dia 17 de julho em Brasília, na $48^{\circ}$ Cúpula de Chefes de Estado do Mercosul e Estados Associados. Foram identificados cinco tópicos que caracterizam os modos de conceber o Mercosul: 1. Mercosul como necessidade e ferramenta; 2. caminho a seguir; 3. Mercosul para os povos; 4. diferenças e dificuldades; 5. união natural e comunidade de destino. $O$ tratamento dos tópicos adotou a Análise do Discurso como prática interpretativa, a fim de revelar as diferentes estratégias discursivas empregadas pelos mandatários da região.
\end{abstract}

Palavras-chave: Análise do Discurso; Mercosul; representações.

\begin{abstract}
This paper analyses different representations that Latin American leaders have towards the Mercosur. In order to achieve this purpose, we have examined a corpus composed of two particular events: the Mercosur Ordinary Meeting occurred on December 17th 2014 in the city of Paraná, Argentina, during the 47th Summit of Heads of State of Mercosur; and the Plenary Session of the 48th Summit of Heads of State of Mercosur and Associated States, that took place on July 17th 2015 in Brasilia (Brazil). We have identified five topics that characterize the ways Mercosur is conceived: 1. Mercosur as a necessity itself and as a tool; 2 . the path to be followed; 3 . Mercosur for the people; 4. differences and difficulties; 5. natural union and ultimate community. These topics have been studied upon Discourse analysis approach as an interpretative practice. Our aim was to reveal different speech strategies folded out by regional leaders.
\end{abstract}

Keywords: Discourse Analysis; Mercosur; representations.

\footnotetext{
${ }^{1}$ Mestrando em Análise de Discurso (Universidad de Buenos Aires) e em Ciências Sociais e Humanidades pela Universidade de Buenos Aires. http://www.escrituraylectura.com.ar/semiologia/sedes escobar.php.

2 Doutoranda em Linguística (Universidad de Buenos Aires) e mestranda em Análise de Discurso (Universidad de Buenos Aires). http://www.escrituraylectura.com.ar/semiologia/sedes_ciudad.php.
} 
Resumen. El presente trabajo indaga en las representaciones que diversos líderes latinoamericanos tienen acerca del Mercosur. Para ello, se analiza un corpus compuesto por dos encuentros específicos: la Reunión Ordinaria llevada a cabo el día 17 de diciembre de 2014 en la ciudad de Paraná, Argentina, en el marco de la $47^{\circ}$ Cumbre de Jefas y Jefes de Estado del Mercosur, y la Reunión Plenaria realizada el día 17 de julio de 2015 en Brasilia, en la $48^{\circ}$ Cumbre de Jefas y Jefes de Estado del Mercosur y de Estados Asociados. Se han identificado cinco tópicos que caracterizan los modos de concebir el Mercosur: 1. el Mercosur como necesidad y herramienta; 2. el camino a seguir; 3. Mercosur para los pueblos; 4. diferencias y dificultades; 5. unión natural y comunidad de destino. El tratamiento de los tópicos se ha realizado adoptando el Análisis del Discurso como práctica interpretativa, con el fin de relevar las diferentes estrategias discursivas desplegadas por los mandatarios de la región.

Palabras clave: Análisis del Discurso; Mercosur; representaciones.

\section{Introducción}

El propósito del presente trabajo es analizar las particularidades con que los diferentes mandatarios de los países miembros del Mercosur construyen y reproducen determinadas representaciones acerca de la integración regional. Específicamente, nos interesa observar las estrategias discursivas que se implementan en ese sentido en ocasiones de reunión internacional, en que se despliegan tanto acuerdos como disidencias habilitados por la situación de interacción. Para ello, se abordará un corpus compuesto por dos encuentros específicos: la Reunión Ordinaria llevada a cabo el día 17 de diciembre de 2014 en la ciudad de Paraná, Argentina, en el marco de la $47^{\circ}$ Cumbre de Jefas y Jefes de Estado del Mercosur, y la Reunión Plenaria realizada el día 17 de julio de 2015 en Brasilia, en la $48^{\circ}$ Cumbre de Jefas y Jefes de Estado del Mercosur y de Estados Asociados. Consideramos que en esos encuentros se ponen en juego diversos posicionamientos ideológicos que muchas veces entran en tensión y que responden a diferentes concepciones acerca de la región. En particular son interesantes estas reuniones porque ocurren en contexto de cambio de los procesos políticos en los países que integran el bloque y en sus presidentes.

Adoptando el Análisis del Discurso como práctica interpretativa (ARNOUX, 2006) se estudiarán las operaciones discursivas que se despliegan para caracterizar el objeto discursivo Mercosur, con el fin de inferir las representaciones de los mandatarios sobre él. Realizaremos esta caracterización a partir de la identificación de diferentes tópicos ${ }^{3}$ que se activan en los discursos sobre la integración.

\footnotetext{
${ }^{3}$ Los conceptos de tópico, tópica, topoi, lugar común y específico, entre otros afines, han sido definidos de diversas maneras, desde las primeras acepciones de Aristóteles (2005), hasta su relectura por Roland Barhtes (1997) y, en la actualidad, por Ruth Amossy (2000). Esto genera, muchas veces, una dificultad de delimitación de estos conceptos tan próximos. En nuestro caso, tomamos la noción de tópico como una forma discursiva particular que permite identificar elementos dóxicos (AMOSSY, 2000), aunque no necesariamente él se realice mediante un mismo sintagma cristalizado. En este sentido, los tópicos analizados permiten identificar las representaciones sociales (ABRIC, 2001) que los discursos de los mandatarios activan.
} 
A continuación, se analizará el corpus considerando a la vez las dos reuniones indicadas. El análisis se organizará en cinco tópicos que estructuran las representaciones en torno a la integración regional: 1. Mercosur como necesidad y herramienta, 2. Camino a seguir, 3. Mercosur para los pueblos, 4. Diferencias y dificultades, 5. Unión natural y comunidad de destino. Luego se expondrán las consideraciones finales y se delinearán pasos para investigaciones futuras.

\section{El Mercosur como necesidad y herramienta}

La presente etapa del capitalismo puso en crisis el esquema político institucional de los Estados-nación. Esto llevó a que los países construyeran integraciones regionales como formas de actuar en el mundo (GARCÍA DELGADO, 1998). En el marco de estos procesos sociohistóricos, surge el Mercosur a fines del siglo pasado. En la actualidad, aún persisten las representaciones acerca de la necesidad de la integración como forma de constituirse en un actor global relevante. El objetivo buscado es lograr cierta independencia en las decisiones políticas y un equilibrio en las relaciones de intercambio comercial.

En los discursos de las reuniones analizadas, se formula la idea de la necesidad de la integración: "Configurar una nueva arquitectura hoy es posible. No solamente es un sueño, un discurso o una arenga política: es una necesidad de urgencia y una posibilidad" (MADURO, 2015) ${ }^{4}$. Esta representación del carácter necesario del Mercosur se sostiene en un razonamiento pragmático (CHARAUDEAU, 2009) basado en la conveniencia que asigna un fin práctico a la integración. Además, se observa en la cita de Nicolás Maduro el contraste entre esta finalidad práctica y "un sueño", "discurso", "arenga política", es decir, lexemas que remiten a la construcción simbólica o imaginaria que la región también necesita para crear y sostener un sentido de pertenencia. El cotejo con esta última característica muestra que se prioriza la necesidad en tanto se la califica de urgente.

La apuesta por la integración con la Unión Europea, cuestión que se está debatiendo en las reuniones consideradas, también es enmarcada por Horacio Cartes en esta lógica pragmática de la necesidad: "Los términos en que logremos los mecanismos de esa integración intercontinental [con la Unión Europea] serán decisivos para progresar hacia los otros acuerdos, que por imperio de la globalización serán necesarios" (CARTES, 2015). En este caso, la obligatoriedad se representa como mandato impuesto debido a la relación de fuerza que implica la metáfora de la globalización como imperio. Es interesante observar cómo el carácter colonizador de las potencias europeas se desplaza hacia el proceso de globalización, mientras América Latina sigue ocupando un rol de "colonizado" o subordinado. De esta manera, se representa como necesario el acuerdo con la UE y se despoja a ese acuerdo de una integración asimétrica, inconveniente o jerarquizada, al desplazarse el histórico rasgo colonial al proceso global. José Mujica, por el contrario, formula el carácter necesario de esa unión, pero advierte acerca del peligro que puede implicar:

\footnotetext{
${ }^{4}$ Las citas de los discursos del corpus han sido tomadas de las páginas oficiales de las presidencias de cada país y/o desgrabadas de la filmación completa de las reuniones. Estas están disponibles en: https://www.youtube.com/watch?v=H0ZtG7a9Gjk https://www.youtube.com/watch?v=f_LMd78ucOI (2015). Última consulta: 10/06/2016.
} 
Si en compensación a ese comercio cada vez más fuerte y más creciente y demandante abrimos nuestra tranquera, adiós con nuestra industrialización y posibilidades. Estamos unidos por un rencor a una relación comercial inevitable, que la necesitamos como el pan porque es oxígeno pero que también nos puede matar. Este es un problema político que hay que pensarlo. (MUJICA, 2014)

En el fragmento del expresidente uruguayo se utiliza el recurso de la comparación para resaltar el carácter necesario de la unión; sin embargo, a partir del uso del adversativo se opone a esa necesidad la inconveniencia, por lo que se orienta la argumentación hacia el plano de lo político y la evaluación de esa relación. Por otra parte, Mujica lleva al extremo el razonamiento práctico utilitario al colocarlo sobre la base del tópico vida/muerte. Por un lado, la unión es conveniente, es una forma de supervivencia; mientras que, por el otro, si se hace sobre la base de intercambios inconvenientes, puede ser fatal.

En el mismo sentido que la lógica pragmática de la necesidad, se construye una representación del Mercosur como medio para lograr determinados fines. Frente a la incertidumbre del comercio mundial de los últimos años y sus diversas crisis, Dilma Rousseff afirma:

O Mercosul é uma das ferramentas importantes nessa estratégia. O comércio intrarregional cresceu quase 12 vezes desde a criação do bloco, enquanto o comércio mundial, no mesmo período, multiplicouse por cinco. (ROUSSEFF, 2015)

El carácter instrumental del Mercosur se funda en un discurso tecnocrático que mide ventajas y desventajas, medios y fines, y coloca en un primer plano la dimensión económica del bloque: "El papel económico del Mercosur como instrumento estratégico de inserción de nuestros países en la economía global y como medio para acelerar el crecimiento económico y el bienestar de nuestros pueblos debe ser enfatizado en la agenda del bloque" (CARTES, 2015). El vocabulario económico se evidencia en la adjetivación de los núcleos de sintagmas nominales que refieren al Mercosur como medio: "una herramienta idónea" (CARTES, 2015), "la eficaz herramienta" (CARTES, 2014).

Estas representaciones de la integración como "necesidad", forma de "supervivencia", "mandato de la globalización" o como instrumento para lograr la inserción en el mercado mundial caracterizan la coyuntura presente. Aunque también la actualidad se representa como un momento excepcional, incomparable a cualquier otra etapa histórica en las relaciones entre los países suramericanos:

Fizemos do Mercosul a mais abrangente iniciativa de integração já empreendida na nossa América Latina. (ROUSSEFF, 2014)

Nunca el continente suramericano y nuestra América Latina había tenido una situación de tanto empuje, de tanto esfuerzo, de insurgencia, de nuevos liderazgos absolutamente soberanos e independientes que

\footnotetext{
5 Todas las cursivas son nuestras.
} 
buscamos la prosperidad de nuestros países, la igualdad. (MADURO, 2014)

Esta construcción de la "excepcionalidad" en los dos fragmentos precedentes contrasta con la "imposición de la globalización" mencionada anteriormente, en tanto para Maduro son sujetos ("liderazgos"), o de acuerdo con Rousseff, es el colectivo latinoamericano ("hicimos"), los agentes constructores de esa situación singular. Se produce así una tensión entre los mandatarios: de un lado, están los que afirman que es la imposición de la coyuntura la que obliga a la unión; del otro, los que sostienen que es la acción de los líderes la que vuelve el presente un momento excepcional para lograrla.

Por otra parte, el carácter excepcional se construye a partir de la comparación con otros momentos de la historia: "Nunca el continente..." (MADURO, 2014). El uso del adverbio establece la relación diferencial respecto de otros momentos a la vez que enfatiza la aserción.

La singularidad del momento se complementa con un corte histórico en los últimos años respecto a la trayectoria del propio bloque. Mientras Tabaré Vázquez representa una continuidad de un proceso sin agentes, Maduro formula un corte que se produce con la aparición de líderes de la región:

Para mí es un honor y un placer estar nuevamente en este ámbito tan importante, en este proyecto proceso de integración regional que lleva ya casi 25 años y 48 cumbres. (VÁZQUEZ, 2015)

Hay un nuevo Mercosur [...] El nuevo Mercosur nació al calor de los liderazgos que fueron surgiendo, del presidente Lula, Kirchner, Tabaré, de los liderazgos del presidente Hugo Chávez que tanto empeño obsesivo puso porque nosotros regresáramos a donde jamás debimos haber salido, a nuestro Suramérica. (MADURO, 2014)

Tabaré Vázquez no refiere un corte en el trayecto del Mercosur, ni siquiera en aquel momento en 2005 cuando él, junto con el resto de los mandatarios, rechazó el acuerdo del área de Libre Comercio entre las Américas (ALCA). En este sentido, privilegia la continuidad del proceso, como si éste se hubiese autogestado o "autodesarrollado". En cambio, Maduro establece un corte histórico en el proceso de integración a partir de la aparición de "Lula, Kirchner, Tabaré (...) Chávez", quienes forjaron el "nuevo" Mercosur, representado como retorno a un espacio común de donde “jamás" se debió salir.

Si bien algunos ratifican los avances en términos de integración debido al impulso de los últimos años dado por los gobiernos denominados progresistas, también se formulan dudas o se cuestiona la lentitud en alcanzar metas. Vázquez reconoce logros pero presupone, a través del sintagma nominal, que el Mercosur estuvo "estancado" los últimos años: "quiero congratularle por los avances y logros que hubo en esta reunión para la reactivación de un Mercosur que es vital para la vida de nuestros países y de nuestros pueblos" (VÁZQUEZ, 2015).

Como señalamos anteriormente, el presidente uruguayo al nominalizar los procesos elude la responsabilidad de los agentes. Por el contrario, Cristina Fernández de Kirchner y Horacio Cartes la hacen explícita: 
al ver el mapa uno advierte claramente el potencial como mercado de consumo, como mercado comercial que tenemos y que todavía no hemos explotado suficientemente. (FERNÁNDEZ, 2015)

No podemos darnos el lujo de quedarnos rezagados, como ha ocurrido en los últimos años con la participación en el comercio mundial. (CARTES, 2014)

Fernández, con el uso del adverbio "suficientemente", presupone que hubo una explotación del mercado que llevaron adelante, pero que podría ser mayor teniendo en cuenta el mercado que conforma todo el territorio de los países que integran el bloque. Cartes, a partir del uso del "nosotros", plantea la responsabilidad presente para enfrentar los desafíos comerciales, pero utiliza la forma impersonal "ha ocurrido" para referir lo que no se hizo en el pasado. De esta manera, desliga a los presentes de esa responsabilidad al eludir el agente. Contrasta lo dicho por Cartes con lo presupuesto por Rousseff en la construcción nominal "preservar as conquistas dos últimos anos" (ROUSSEFF, 2015).

\section{El camino a seguir}

La discusión en torno a las metas a alcanzar expone distintos puntos de vista acerca del futuro del Mercosur. Una de las formas de definir al bloque es la configuración de un camino a seguir que delineará el tono de la integración regional. Este tópico remite a la memoria fundacional de los acuerdos continentales, patentada en el Acta de Iguazú firmada por Argentina y Brasil en 1985, donde se convoca a construir "nuevos caminos en la búsqueda de un espacio económico latinoamericano". Se verá que la dimensión económica es predominante en los discursos de los enunciadores aunque adopta diversos matices. El camino a seguir se presenta, en términos generales, o como un deseo o como un deber.

En el primero de los casos se encuentra el discurso de Cristina Fernández, focalizado en los logros:

Estoy absolutamente convencida de que logrando una mejor distribución del ingreso hacia adentro de cada uno de nosotros vamos a lograr una mejor distribución del ingreso regional, un mayor crecimiento cualitativo de nuestros recursos, de nuestras posibilidades, de nuestro valor agregado que debemos hacer cada vez con mayor intensidad. Que no significa renegar de integrarnos a otras áreas del mundo ya más consolidadas económicamente. Pero que esa integración a otras áreas más consolidadas económicamente no sea en detrimento de nuestra región, sino que sean un win-to-win, un ganar-ganar. [...] lo que tenemos que lograr con la integración es poder exhibir ante nuestras sociedades, ante nuestros compatriotas, que esa integración es altamente beneficiosa para el pueblo y fundamentalmente para los sectores más vulnerables y que más necesitan de la presencia del Estado. Porque, además, porque además no es una cuestión de sensibilidad política o sensibilidad emocional, es una cuestión de inteligencia económica. (FERNÁNDEZ, 2014) 
El gerundio marca el carácter futuro de las medidas a tomar, cuyas consecuencias se traducen en logros conjuntos indicados en un futuro imperfecto perifrástico que los vuelve indiscutibles. El tono optimista está dado además por medio de diferentes estrategias del énfasis de la aserción (ANGENOT, 1982), como la enumeración de los resultados y la adjetivación relativa al crecimiento, asociado a la vez con el pronombre posesivo en primera persona del plural. La adopción de políticas internas ("hacia adentro de cada uno de nosotros") es la condición para el bienestar común de la región, centrado en factores de índole económica, como la distribución de ingresos y el aumento de recursos. Pero no solo estos objetivos sino también el modus operandi del Mercosur ("una cuestión de inteligencia económica") asignan al bloque un carácter predominantemente económico. El marco de valoración positiva permite a la enunciadora incluir un mandato ("debemos hacer") y una consigna política sobre la integración en términos de ganancias: "que sea un win-to-win". Se trata de un futuro que se teje desde un presente globalizado y que entiende el acuerdo regional tal como fue formulado en el origen del Mercosur: como una forma de conseguir una inserción en el panorama internacional. La caracterización introducida mediante la negación polémica (GARCÍA NEGRONI, 2009) "que esa integración a otras áreas más consolidadas económicamente no sea en detrimento de nuestra región" traza los rasgos de una oposición entre el Mercosur y "otras áreas". La configuración de un "otros" que detenta poder antecede el imperativo bajo las formas "no se puede" y "tenemos que". En este último caso, el énfasis responde a la modalidad del mensaje (MAINGUENEAU, 1980) que escapa a la conformación frásica habitual y hace hincapié en los pasos futuros.

Todos juntos debemos afianzar en la región una verdadera, justa y solidaria integración, que apunte fundamentalmente a crear las mejores condiciones de vida para nuestra gente. Hoy celebramos un nuevo encuentro, precedido de una nueva serie de reuniones de los órganos del Mercosur. ¿Qué concluyen con la Cumbre de los Jefes de Estado? Pienso, no debería convertirse en un rito que se renueva cada seis meses sino en la efectiva concreción de nuevos logros, en la consecución de los objetivos trazados en el Tratado de Asunción suscrito ya hace 23 años. Nuestro desafío permanente: fortalecer el Mercosur. Esta es una tarea común que nos obliga a priorizar en un marco de consenso aquellas acciones que permitan acelerar la marcha de nuestro proceso y proyectarnos como protagonistas en el marco de un contexto internacional más exigente y competitivo. (CARTES, 2014)

En el fragmento de Cartes, la combinación del 'nosotros' y el imperativo hace hincapié en el futuro de una integración caracterizada por la solidaridad. Pero, además, a lo largo del discurso del mandatario hay una dicotomía realidad/virtualidad en que se concentran las críticas al accionar del Mercosur y las bases para el quehacer futuro. Mediante la pregunta retórica y el tiempo condicional que actúa como mitigador, el mandatario introduce una polémica acerca de las reuniones del bloque y define el porvenir a partir de la negación. La crítica descansa en el origen del acuerdo regional y en las disidencias entre aquel pasado y el presente subyacente al "no debería" polémico (GARCÍA NEGRONI, 2009). Los logros, en este caso, son un anhelo, no una concreción. El posesivo se detiene en "desafío permanente" y es reforzado mediante la elipsis verbal. La comunidad se ancla en ese aspecto fáctico cristalizado en el sintagma "tarea común" y dirigido al cumplimiento de metas comerciales. 
La concreción a que alude Cartes se asocia con el comercio, tal como afirmaba Fernández un rato antes:

Por eso creo que en todas esas discusiones que tengamos como Mercosur debe primar primero pragmatismo, realismo y sinceridad a la hora de la discusión. Estamos dispuestos a discutir de igual a igual, pero poniendo los números sobre la mesa. Además, esto es mucho más fácil que hacer una integración política. Porque una integración política siempre trae los matices subjetivos de las ideologías, de los proyectos, de las pertenencias. Pero cuando hablamos de comercio, señores, estamos hablando de objetos claros, contentos, medibles, pesables... (FERNÁNDEZ, 2014)

En consonancia con su par paraguayo, la mandataria argentina subraya el pragmatismo como rasgo de las políticas del Mercosur. La integración de índole comercial contrasta con la política, que queda desplazada y superada por el adversativo "pero".

El discurso de Mujica deshecha, como el de Cartes, el optimismo argentino inicial:

La integración será posible si hay voluntad política y se construye, y nunca va a ser un producto que surge espontáneamente del mercado. Nadie puede asegurar que el mercado integra. El mercado es fundamental y hay que entenderlo y atenderlo y puede ser una fuerza creadora pero también puede ser una fuerza descuartizadora si no existe voluntad política. Y esa voluntad política debe de contribuir también a crear infraestructura; no solo comercio, además infraestructura. Debe de luchar por integrar la inteligencia, las universidades, los programas comunes, los profesionales, sobre todo la academia tecnológica. Debemos de luchar por nuestro cerebro, por nuestro sistema de investigación. (...) No hay soberanía de largo plazo si no hay conocimiento nuestro. La batalla del futuro es en rededor del conocimiento. $\mathrm{Y}$ es un craso error que no podamos juntar el esfuerzo universitario latinoamericano y tener un sistema común de investigación. Porque llegamos tarde, porque nos llevan enorme ventaja, porque el siglo en el que entramos es el siglo de la biología, porque estamos en la última reserva agrícola que le queda a la humanidad. Y es criminal que la biología no sea el centro de la preocupación del Mercosur. (MUJICA, 2014)

Para Mujica, la integración no es económica, sino que encuentra su motor en la "voluntad política". Se trata de una posibilidad que requiere de ciertas condiciones (encabezadas por el incluyente "si") y que muchas veces adopta la forma negativa "si no" que señala, junto con los adjetivos "descuartizadora" y "criminal", el carácter amenazante del mercado. Por otro lado, el 'nosotros' se torna protagonista de un mandato que adopta la forma de lucha y que hace del conocimiento la principal herramienta para la independencia económica. En contraste, la tercera persona del plural alude a quienes detentan el poder, los contradestinatarios (VERÓN, 1987), y consagra la oposición nosotros/ellos que irriga el plan de acción en un marco de desventaja.

Las dificultades con que se vincula el camino del Mercosur se presentan también en las palabras de Evo Morales, vinculadas con la configuración de un enemigo común: 
Y mi pedido, hermanas Presidentas y hermanos Presidentes, sería importante en nuestros grupos de trabajo, especialmente en el aspecto financiero y económico, hagamos, haya una reunión permanente. Los enemigos históricos de los pueblos de América Latina y el Caribe, y especialmente los gobiernos que estamos acá o de Unasur, que nos digan qué están preparando o qué problema podemos tener. [...] Nosotros también tenemos que calcular que esta rebaja del petróleo, el barril del petróleo cuánto nos va a afectar, cuánto nos afectaría, un poco para prevenir y para prepararnos para enfrentar esta clase de agresiones económicas. (MORALES, 2014)

El carácter adversativo del par nosotros/ellos se sustenta en la historia de la región. Los obstáculos se presentan no solo mediante el señalamiento de la amenaza sino también por el mandato de defensa ante conflictos futuros. El campo léxico asociado a la guerra enfatiza la hostilidad externa y, por momentos, se resuelve en un tono desafiante e incluso de arenga: "que nos digan qué están preparando".

Por último, Dilma Rousseff asocia el camino con un mandato que consiste en afianzar una integración todavía débil en un panorama global amenazante:

Frente a este cenário mundial, nós temos que dobrar a nossa aposta na integração regional. Nós temos de dobrar essa aposta e reforçar nossas capacidades e nossas alternativas. A determinação, eu acredito, de todos os países, presidentas e presidentes aqui presentes, eu acho que é clara: fazer do Mercosul uma região e uma união aduaneira cada vez mais forte. Fazer do Mercosul um espaço em que nós possamos compartilhar infraestrutura, como nós sempre falamos, mas também reforçar as nossas relações comerciais e de investimento. (ROUSSEFF, 2014)

Las formas "tenemos que" y "lo que tenemos que hacer es" establecen una gradación en la fuerza del imperativo sobre los integrantes del Mercosur. Las aserciones "tenemos la determinación" y "es claro" muestran como evidente el camino de convertir el Mercosur en un acuerdo basado en la "unión aduanera" y en la posibilidad de compartir recursos. En este sentido, el bloque es definido nuevamente no por lo que es sino por lo que debe ser.

\section{Mercosur para el pueblo}

Como se ha observado en fragmentos anteriores, la idea de que la integración está al servicio del pueblo es recurrente en los discursos y también define al bloque. El Tratado de Unasur de 2008 marca la orientación de los objetivos pronunciados en las Cumbres del Mercosur aquí estudiadas:

convencidas de que la integración y la unión suramericanas son necesarias para avanzar en el desarrollo sostenible y el bienestar de nuestros pueblos, así como para contribuir a resolver los problemas que aún afectan a la región como son la pobreza, la exclusión y la desigualdad social persistentes... (TRATADO DE UNASUR, 2008) 
$\mathrm{Al}$ respecto, afirma Dilma Rousseff:

Eduardo Galeano, que há pouco nos deixou, escreveu que a pobreza não estava escrita nos astros, não era um destino imutável; e que a solidariedade, sim, está inscrita na nossa alma. Suas palavras devem ter inspirado a ação de nossos governos na busca de melhores condições de vida para os nossos povos. Os países da região engajaram-se, nos últimos anos, na execução de políticas econômicas, com foco no combate à pobreza, na melhor distribuição de renda, na promoção do emprego e dos ganhos salariais. (ROUSSEFF, 2015)

Con la alusión a la literatura de Galeano, la apelación a un factor cultural que teje una identidad común determina el mandato originario de servir a los pueblos. La inscripción espiritual de la solidaridad forma parte, además, de la unión natural que rige el objetivo de mejorar la calidad de vida de los gobernados disolviendo las desigualdades sociales. El cumplimiento de ese fin se despliega en un fragmento narrativo que realza la emotividad mediante la enumeración de aspectos de la política económica regional. Las adjetivaciones y el posesivo 'nuestros' ('nossos') junto con el plural van en esa misma dirección de valoración positiva del carácter representativo de los gobernantes del Mercosur.

En 2015, cuando Bolivia es aceptada como nuevo integrante del bloque, Morales enfatiza esta idea:

\begin{abstract}
reconocemos, respetamos y valoramos el liderazgo de Argentina y Brasil en desarrollo tecnológico. Quisiéramos dentro de ese trabajo en conjunto, ampliar nuestros mercados para el bien de todas y todos. De verdad este ingreso al Mercosur es para que Bolivia siga creciendo. Con comercio de complementariedad, de solidaridad, que a veces practicamos con algunos países en mi gestión. Por eso quiero decirles, tenemos muchas esperanzas de cómo integrarnos en tema de comercio, en temas de integración territorial, en lo social y lo cultural. No perdemos la esperanza de que Bolivia siempre acompañará los procesos de integración. Espacio, organismos que vamos creando, siempre y cuando estos organismos estén al servicio de nuestros pueblos, que los pueblos ganen, de estas organizaciones, como Mercosur, Celac, Unasur, que estén al servicio de nuestros pueblos. (MORALES, 2015)
\end{abstract}

El objetivo mercantil se explica por el fin último del bienestar popular y de la reducción de las asimetrías internas manifestadas en el lugar distintivo que el enunciador asigna a Argentina y Brasil. El crecimiento económico, indicado en los lexemas "desarrollo", "ampliar", "creciendo", entre otros, define la integración dada por el "trabajo conjunto" y la "complementariedad". Acorde a esta voluntad, el presidente boliviano construye un 'nosotros' nacional caracterizado por las esperanzas de integración, pero con una condición: el Mercosur debe estar subordinado a las voluntades populares. Es significativa la elección del verbo ganar ("que los pueblos ganen”), subjetivema (KERBRAT-ORECCHIONI, 1999) que contrasta con el mencionado "winto-win" que Fernández adjudicaba a la relación entre bloques. Morales relaciona las desigualdades sociales dentro de la región y, más aún, dentro de cada país, no solo con lo comercial sino también con el vínculo entre representantes y representados y con las dimensiones territorial, social y cultural. 
En el discurso de Vázquez, la mejora de las condiciones de los pueblos es asociada, como en Fernández (2014), a la relación entre Mercosur y otros países del mundo:

tal vez para algunos negociadores puede tomarse veinte años para realizar puntillosamente su tarea, pero hay gente que tiene otras urgencias, no puede esperar más para mejorar su vida. Y el acuerdo planteado entre el Mercosur y la Unión Europea tiene esa finalidad: lograr una mejor calidad de vida para nuestros pueblos. (VÁZQUEZ, 2015)

Mientras Vázquez utiliza como sinónimos los lexemas "gente" y "pueblos", Mujica marca una distinción social entre ambos:

estas cuestiones de la integración no las sienten los pueblos. Esto es de la gente que lee tres diarios por día, que tiene cierta formación intelectual, que tiene apego a la política. Y hasta que esto no baje al seno de las masas, de los que tienen dificultad para comprarse un par de zapatos, de los que tienen dificultad de llegar a fin de mes, si la gente no entiende que el destino de nuestros hijos se juega en estas cosas, para que nuestros descendientes no estén subordinados en un mundo de superpotencias. (MUJICA, 2014)

El mandatario uruguayo sostiene que el Mercosur no considera a los pueblos y, así, apoya la noción de integración como cumplimiento del mandato popular. La diferencia es que, en lugar de presentarlo como una característica positiva del Mercosur, lo considera como una falencia que es necesario comprender y como una lucha que es necesario emprender. La integración está marcada por la imperancia ante un escenario mundial amenazante y tiene como protagonistas a las "masas". El contraste con las "superpotencias" rige el trazado de un futuro encarnado por las generaciones venideras.

\section{Diferencias y dificultades}

Los enunciadores exponen diversos tipos de problemas, entre los que se pueden distinguir a. aquellos que hacen a la situación interna de la región y b. aquellos vinculados con el posicionamiento del bloque en el panorama mundial. Entre los primeros, son centrales 1. las desigualdades sociales dentro de cada país y 2. las asimetrías entre los Estados-miembro del Mercosur. Entre los segundos, hay diversos obstáculos y dificultades que se asocian a las relaciones de poder económico y político y a la delimitación de una antítesis nosotros-ellos. Este tipo de problemas A. debe ser afrontado a partir de la resolución de las diferencias internas, y B. tiene su contracara en la configuración de una región latinoamericana caracterizada por la paz y de democracia.

\subsection{Desigualdad social y asimetrías internas}

La voluntad popular tiene su contraparte en las desigualdades internas que los países del Mercosur deben resolver para lograr la integración regional. Tal es la postura de Tabaré Vázquez, al referirse al Fondo de Convergencia Estructural del Mercosur 
(FOCEM) autodefinido como "el primer mecanismo solidario de financiamiento propio de los países del MERCOSUR y tiene por objetivo reducir las asimetrías del bloque"6.

El 2015 es el último año en que los Estados-parte realizarán aportes al FOCEM, siempre y cuando no se apruebe una nueva decisión. Y felizmente, para regocijo de todos nosotros, en atención a las asimetrías que tiene el bloque, se ha aprobado nuevamente por un plazo de diez años continuar con este proyecto tan importante para nuestros países, para nuestros pueblos. (VÁZQUEZ, 2015)

La continuidad del FOCEM habilita una dimensión emocional en las palabras del mandatario uruguayo, construida mediante los subjetivemas "felizmente" y "regocijo", el nexo copulativo "y" que sigue a la cita textual, la adjetivación en "todos nosotros" que amplía el colectivo de la primera persona y la repetición final "para nuestros países". El enunciador vincula la decisión sobre el FOCEM con el bienestar popular y concreta, así, el cumplimiento de la función representativa de los líderes del bloque. Es subrayable que la condición para cumplir dicha función es la reducción de las asimetrías entre los países: la integración de los Estados-miembros se presenta como un factor determinante en las políticas internas de cada nación.

En la misma dirección, las asimetrías y la necesidad de disminuirlas se hacen presentes en las palabras de Rousseff, quien define al Mercosur por su función de equilibrar e igualar económicamente a los países del bloque: "nosso compromisso também se estende à integração produtiva, com redução das assimetrias entre nossos países" y, más adelante, "o Mercosul é, também, um fator, um grande fator de mitigação de assimetrias e de apoio a um desenvolvimento equilibrado entre os sócios" (ROUSSEFF, 2015).

El discurso de Evo Morales adopta, en cambio, un tono imperativo:

Saludos las palabras de la Presidenta de Argentina, de Brasil, cuando hablan de cómo acabar con las asimetrías, esa es una lucha permanente, cómo achicar esas diferencias económicas. Esa es nuestra obligación, nuestra responsabilidad. Esa una gran misión nos da nuestros pueblos con sus votos para servir mejor al pueblo boliviano y al pueblo latinoamericano. (MORALES, 2014)

Los pronombres en primera persona del plural responsabilizan directamente al enunciador y sus coenunciatarios en "una lucha permanente". Además, el mandatario delinea un objetivo que no consiste en reducir las asimetrías sino en "acabar" con ellas, dado que el deber no solo tiene en la mira a "nuestros pueblos" sino que procede de ellos.

Para Cartes, en cambio, la disminución de las asimetrías no define al Mercosur sino que caracteriza el proceso de integración propuesto: "Aspiramos a un proceso de integración que vaya reduciendo las asimetrías y superando las dificultades, que deje de lado el mero discurso y pase a la acción y a las medidas concretas que hagan efectiva la integración" (CARTES, 2014). No se trata de una función establecida sino de una posibilidad, que se posiciona del lado de la concreción en la dicotomía efectivo/virtual. El carácter futuro de la igualdad entre los países se ve no solo en el lexema "aspiramos"

6 http://focem.mercosur.int/es/ (última consulta: 10/06/2016). 
sino también en el predominio del modo subjuntivo. Esta voluntad es, más adelante, un mandato que tiene antecedentes en el mismo enunciador:

Paraguay ha venido insistiendo en que el Mercorsur debe contribuir en los hechos a la superación de las asimetrías existentes entre nuestras naciones. (...) En el nuevo escenario que nos presenta el Mercorsur ampliado con el ingreso de nuevos Estados-partes, con las características específicas de cada uno de nuestros países, debemos asegurar un trato más considerado a las economías más pequeñas y vulnerables para garantizar la convergencia y el fortalecimiento de un verdadero proceso de integración. (CARTES, 2015)

El mandato cobra fuerza por medio del adjetivo "existentes" que configura un estado actual concreto caracterizado por la desigualdad. En segundo lugar, las asimetrías ya no deben ser reducidas sino superadas, y es primero el Mercosur personificado quien tiene la obligación de hacerlo ("el Mercosur debe") y después el 'nosotros' que agrupa a los diferentes representantes del bloque ("debemos asegurar"). Se configura, asimismo, un espacio que, si bien rechaza asimetrías, acepta diferencias: "el Mercosur ampliado" es abierto a los distintos países y sus particularidades. El problema a resolver son las desigualdades de índole económica. En este sentido, la región se acerca a la Unión Europea a la vez que se distancia de ella mediante la apropiación y resignificación de su lema "la unidad en la diversidad".

\subsection{Mundo difícil y región de paz}

Por otro lado, las alusiones a las dificultades con que se enfrenta la integración están generalmente ubicadas fuera de la región.

Porque la integración no puede confundirse con la subordinación o con la cooptación de un sistema económico que ya se ha integrado por parte de otro sistema económico integrado. Debe ser en igualdad de condiciones. Y en igualdad de condiciones significa tener en cuenta las asimetrías que existen entre bloque y bloque, porque claramente los bloques con los cuales tenemos que negociar y tenemos que integrarnos tienen tal vez un nivel superior al nuestro y entonces hay que tener en cuenta esas asimetrías. (FERNÁNDEZ, 2014)

En este caso, la integración es con el continente transatlántico. Las desigualdades, en palabras de Fernández, homogeneizan al Mercosur y lo distinguen de UE. Se trata de diferencias de índole económica, que ubican a la región en una posición de desventaja expresada de forma mitigada ("tienen tal vez un nivel superior al nuestro") y resuelta mediante un mandato (“debe ser en igualdad de condiciones").

La incidencia de la economía mundial en la consolidación del Mercosur se expone también a continuación:

Com isso, logramos evitar que os efeitos mais nocivos da crise económica financeira global contaminasse nossas economias. Esta crise, no entanto, tem se mostrado persistente. A recuperação das 
economías avançadas ainda é frágil e as perspectivas de um novo ciclo de crescimento global continuam incertas. (ROUSSEFF, 2015)

Los problemas financieros del mundo son, según Rousseff, una amenaza ("contaminase") para la resolución de los conflictos internos y trazan un estado actual conflictivo, con "perspectivas" "inciertas". La oposición entre un 'nosotros' y un 'ellos' peligroso se ve acentuada en el enunciado de Maduro:

las fuerzas disolventes andan por allí apostando toda vez a desgajar América y a destruir. Pero el balance es muy contundente, la presidenta Dilma lo decía, es muy contundente el balance de lo que se ha logrado. Mercosur es una maquinaria de vanguardia, de construcción como de hormigas de una integración ahora integral. (MADURO, 2014)

Amparado en la palabra de su par brasileña, el mandatario venezolano caracteriza al Mercosur como una máquina de integración que tiene el poder de frenar los avances externos. Mientras el deíctico "allí" ubica a las "fuerzas disolventes" en una posición antagónica a la del enunciador, el adversativo "pero" niega los intentos del adversario.

Quiero señalar además que la integración es difícil, muy difícil. Tiene una multitud de obstáculos, en nuestra formación cultural, en las tradiciones de Estado nacional, en nuestros espacios políticos, en nuestro corto plazo, donde cada uno de los gobiernos está sometido a las tensiones de los intereses de sus respectivos países. No tiene nada de fácil ni de sencillo, es un largo proceso y duro. Pero necesita voluntad política. (MUJICA, 2014)

Mujica subraya las incidencias que tienen las desigualdades sociales en el logro de la cabal integración de los países del Mercosur, caracterizada como dificultosa y como un proceso que requiere esfuerzo. A diferencia de los enunciados de los otros mandatarios, las tensiones internas de cada país son uno más de los obstáculos con que se enfrenta el bloque, diverso en sus culturas, tradiciones y políticas. Sin embargo, más adelante se observa que esas diferencias ceden lugar a un enemigo externo que impide la paz continental:

quiero señalar además que este continente está tocando casi la paz con la mano, como no lo tuvo durante casi un siglo y pico. Y que debe ser un continente de paz que debe de luchar por la paz en todos los rincones de la tierra. Y debe de levantar su voz porque la guerra contemporánea, si pudo haber guerra justa o injusta, con el salto tecnológico de nuestro tiempo la guerra contemporánea significa el sacrificio de los más débiles siempre. (MUJICA, 2014)

Los conflictos presentes, agrupados en el sintagma "la guerra contemporánea" imponen la primacía de la paz en la región (“debe ser un continente de paz”). La contraparte de las asimetrías mundiales es la ejemplaridad que el Mercosur encarna como espacio de concordia:

na Cúpula Social do Mercosul, nós fortalecemos mecanismos que permitem uma ampla participação dos movimentos sociais na nossa 
cooperação. Esse pluralismo, ele fortalece e dá, sobretudo, pleno sentido à nossa integração, às nossas democracias. (ROUSSEFF, 2015)

Según Rousseff, el pluralismo define la integración y a la vez constituye una segunda oposición que también une a los miembros del bloque. Se trata del pasado dictatorial común, que asigna al 'nosotros' el valor compartido de la democracia:

somos uma região que sofreu muito com as ditaduras. Hoje somos uma região onde a democracia floresce e amadurece. No ano passado, tivemos eleições gerais no Uruguai e no Brasil. Este ano é a vez da Argentina e da Venezuela. A realização periódica e regular desses pleitos demonstra capacidade de lidar com diferenças políticas, por meio do diálogo, do respeito às instituições e da participação cidadã. Temos de persistir neste caminho, evitando atitudes que acirrem disputas e incitem a violência. Não há espaço para aventuras antidemocráticas na América do Sul, na nossa região. (ROUSSEFF, 2015)

Las caracterizaciones que realiza la enunciadora remiten a una historia de sufrimiento que contrasta con los valores presentes. La legitimidad de la gobernancia actual se acentúa en el lugar central que Rousseff le otorga en el camino a seguir: es un deber continuar con la democracia y defenderse de las descalificadas "aventuras" que la niegan. Pero también se vincula con una trayectoria que convierte la preeminencia de estos valores en un logro: "muitos diziam que o Mercosul seria incapaz de construir este acordo comum. Pois fomos capazes" (ROUSSEFF, 2014).

"Somos una realidad democrática, somos un proyecto democrático, inclusivo. Son temas importantes de un Mercosur dinámico, democrático, de los pueblos, que hoy existe. Nosotros nos alegramos que así sea" (MADURO, 2015). En la voz de Maduro, el 'nosotros' adopta una esencia concreta que se puede ubicar fácilmente en la dicotomía trazada anteriormente por Cartes y que se asienta mediante la selección léxica "existe" y "así sea". A su vez, la oposición entre presente y pasado se efectúa mediante el deíctico "hoy".

\section{Mercosur: unión natural y comunidad de destino}

La particularidad que distingue al continente del resto del mundo, dada por la primacía de la paz y por la historia común, se vincula con otro tópico que abarca el vínculo entre unión natural y comunidad de destino.

Así como los Estados-nación se construyeron sobre la base de una comunidad imaginada que funcionó como universo de referencia simbólica común entre sus integrantes (ANDERSON, 1983), las integraciones regionales no están exentas de la constitución de un imaginario que asigne un sentido de pertenencia. Al respecto, Elvira Arnoux (2008b) sostiene que las gestas de las independencias hispanoamericanas forman parte de la memoria discusiva continental y funcionan como horizonte de referencia simbólica. En la reunión se puede observar, por un lado, un desplazamiento entre el uso del "nosotros" que incluye a los integrantes del Mercosur y un "nosotros" que integra a 
los latinoamericanos; por otro lado, como se comentó, se opone al "nosotros" el uso de "ellos" en referencia a los países europeos o bien para mencionar a aquellos que se opusieron a la "natural" unión latinoamericana. El uso de nosotros que define el colectivo y que señala una oposición se evidencia en el recurrente sintagma formulado por José Martí (1981) y cristalizado en la actualidad: "Nuestra América" (CARTES, 2014; ROUSSEFF, 2014; MADURO, 2014). También Cartes utiliza la expresión "Patria latinoamericana" que connota la figura de Bolívar y su postulación de la "Patria Grande".

Además de la ocurrencia de estos sintagmas que nominan el objeto Mercosur a la vez que connotan una tradición histórica, en los discursos se reconocen expresiones que se inscriben en lo que Arnoux (2008b) denominó la matriz de los discursos latinoamericanistas. Según la autora, los componentes que presenta la matriz constituyen la base de la memoria discursiva latinoamericanista, por lo que la inscripción de los discursos en ella orienta la argumentación hacia la integración política de la región (ARNOUX, 2008b, 100). Uno de los componentes de la matriz es la "unión natural". Esta supone la construcción de un espacio homogéneo que deriva de la etapa fundacional de la Independencia y puede tender a borrar las diferencias culturales (ARNOUX, 2008b, 109). Este componente se puede referir por medio del uso de metáforas familiares o biológicas que expresen la unidad sostenida sobre la base de un vínculo "natural".

Y lo que hicimos fue llenar de tensiones a un solo cuerpo social y político, que era América que nacía. Es como que separaran de nuestro cuerpo los brazos, las piernas, los ojos. Desarticularon el cuerpo de la naciente unión. (MADURO, 2014)

En el fragmento precedente, Maduro refiere la "unión natural" a través de la metáfora corporal. Si bien califica al cuerpo de "social y político" lo define como un solo ser biológico ("América que nacía", "nuestro cuerpo"). De esta manera, se desplaza el vínculo histórico hacia una relación naturalizada por la referencia a lo corporal. También se acentúan los lazos de unidad a través de la mención de figuras decimonónicas que representan una historia compartida:

Tal vez algunos de ustedes no sepan pero esta es una tierra muy entrañable en la historia de las luchas emancipatorias argentinas y uruguayas. Tal es así que la bandera de esta provincia, la bandera de Entre Ríos, es la bandera de Artigas. Es la bandera con la franja colorada cruzada. Esta provincia tiene la bandera de Artigas. Miren ustedes cómo estamos mezclados en las historias uruguayos, argentinos, cómo somos una sola cosa, un solo territorio. Por eso es muy especial el estar hoy aquí celebrando esta reunión del Mercosur. Porque hubo en esos hombres y mujeres del siglo XIX, en Ramírez y La Delfina, La Delfina, que era portuguesa, ¿sabías, Dilma? La compañera, la mujer del caudillo de esta provincia del siglo XIX, de Pancho Ramírez, era portuguesa, le decían La portuguesa. Delfina. (FERNÁNDEZ, 2014)

El uso del verbo "somos" define un colectivo determinado por la unidad territorial. Esta vuelve indistinta la pertenencia "uruguaya, argentina, portuguesa" ya que "estamos mezclados". Fernández interpela al resto de los mandatarios para enfatizar la unión ("miren ustedes", "¿sabías, Dilma?"). En esta operación de construcción de un espacio e 
historia común, a la vez que se reivindican las "mezclas", se borran las diferencias culturales y conflictos pasados.

La historia compartida se actualiza a través del uso del conector consecutivo que establece una relación causal entre el pasado y el presente y por las referencias deícticas espaciotemporales: "Por eso es muy especial el estar hoy aquí celebrando esta reunión del Mercosur". La importancia del discurso conmemorativo en los discursos de Hugo Chávez ha sido analizada por Elvira Arnoux (2008a). La autora destaca la recurrencia a las efemérides en los discursos del expresidente fallecido. Sostiene que apelar a estrategias de rememoración y conmemoración es una forma de hacer presente el pasado, por ejemplo, a través de expresiones como "en un día como hoy". Observamos esto mismo en el siguiente fragmento de Maduro, donde la oscilación entre el pasado y el presente funciona estableciendo una continuidad:

Hoy, 17 de diciembre también a esta hora exactamente, una de la tarde, allá en Venezuela estamos recordando los 184 años de la partida del Libertador Simón Bolívar. En Santa Marta. Once años antes, Cristina, once años antes, en 1819, un día como hoy en un lugar muy parecido a Paraná, en el Orinoco, en Angostura, lo que hoy es ciudad de Bolívar, se fundó Colombia. Firmó el decreto de fundación de Colombia, con la unión de las Provincias Unidas de Venezuela, la provincia de Granada y la provincia de Quito. Un gigantesco espacio, geo-humano, geopolítico. Hay que recordar que Nueva Granada y lo que fue Colombia después incluía a Panamá. Era una república caribeña, atlántica, amazónica, andina, centroamericana, pacífica. Un gran concepto, Colombia. Era el concepto de la unión del sur: una unión de repúblicas. Y luego fue Bolívar a la Confederación con Perú y a la fundación, desde el Alto Perú, de Bolivia. Un inmenso territorio. Luego de la muerte de Bolívar, exactamente hace 184 años, se impusieron las fuerzas disolventes de la unión naciente. Fuerzas disolventes que están por allí, que Pepe nombró, la propia presidenta Dilma, la presidenta. (MADURO, 2014)

La expresión "un día como hoy" señala la efemérides enfatizada por la actualización "hoy", "a esta hora exactamente". Por otro lado, algunas referencias juegan con la ambigüedad entre el pasado y el presente, como en la expresión "Once años antes, Cristina, once años antes, en 1819, un día como hoy". "Antes", al posponerse el año que permite identificar la referencia, oscila entre ser una referencia cotextual y una deíctica (KERBRAT-ORECCHIONI, 1999) que remiten al pasado o al presente enunciativo respectivamente. También la referencia espacial es actualizada a través de la identificación del lugar de la fundación de Colombia por medio del nombre actual: "lo que hoy es ciudad de Bolívar". La "mezcla" entre "uruguayos, argentinos y portugueses", ya observada en el fragmento de Fernández, se reproduce aquí apelando al espacio conformado por la entonces Colombia, "mezcla" remarcada además por la enumeración igualadora que menciona diversas regiones americanas: "Era una república caribeña, atlántica, amazónica, andina, centroamericana, pacífica". Por otro lado, a la "unión de repúblicas", ese "inmenso territorio" que nacía -otra vez, la metáfora biológica- se opusieron "fuerzas disolventes", que también pueden ser identificadas en la actualidad, nuevamente a través de la deixis: "Fuerzas disolventes que están por allí, que Pepe nombró, la propia presidenta Dilma, la presidenta Cristina". 
Además de la "unión natural" que inscribe los discursos en la matriz latinoamericanista y, en consecuencia, en una memoria compartida, la unidad se expresa apelando a un futuro común. Arnoux (2008a) sostiene que otro de los componentes de la matriz es el "futuro venturoso", que remite al discurso utópico. Vinculada a él podemos recordar la definición de nación planteada por Otto Bauer:

Nación es un conjunto de seres humanos vinculados por una comunidad de destino [...] comunidad de destino no significa sometimiento a un mismo destino, sino vivencia común del mismo destino, en permanente comunicación y continua interacción recíprocas. (citado en LÓPEZ, 2011)

Dilma Roussef formula:

as medidas que acabo de mencionar, elas provam que nós compartilhamos, de fato, o mesmo projeto. Nós compartilhamos, de fato, uma mesma concepção, mas, sobretudo, nós temos consciência de que nós compartilhamos um mesmo destino. (ROUSSEFF, 2015)

\section{Conclusión}

En el trabajo, se han analizado los diferentes tópicos que recorren los discursos de los mandatarios latinoamericanos para definir y caracterizar el objeto discursivo Mercosur. A la construcción de dichos tópicos subyace la discusión sobre el acuerdo con la UE y sobre el cumplimiento de objetivos y las metas del Mercosur.

En lo expuesto, no se han encontrado posicionamientos radicalmente opuestos sino matices entre los enunciados de los mandatarios e incluso ambigüedades intradiscursivas. Por un lado, se han identificado diferencias entre aquellos enunciadores que, en principio, tienen afinidades políticas. Por ejemplo, la diversa concepción del Mercosur para el pueblo, en Mujica y en Morales; o las distintas ideas entre Vázquez y Mujica sobre el acuerdo con la Unión Europea. Por otro lado, se han notado cercanías entre aquellos líderes que tienen posturas tradicionalmente diferentes. Por ejemplo, Maduro y Cartes coinciden en cuestionar la retórica política y enfatizan la importancia de alcanzar hechos concretos.

Sin embargo, con respecto a las ambigüedades intradiscursivas, Maduro reconoce la urgencia de avanzar en hechos concretos sin dejar de lado el discurso épico relativo a la unión natural. Asimismo, Fernández reivindica la raigambre política del bloque y, a la vez, hace hincapié en la centralidad del factor económico.

En síntesis, se intenta mitigar la actitud confrontativa porque se propicia la continuidad del bloque. En este sentido, a la vez que se avala la heterogeneidad en los discursos, se ubican las amenazas en el exterior y se empiezan a contemplar opciones que antes estaban descartadas, como la Alianza del Pacífico y la Unión Europea. Esta postura podría evidenciar modificaciones en la orientación en el bloque, expuestas, por ejemplo, en los cambios presidenciales de Argentina y Brasil. 


\section{Bibliografía}

ABRIC, J-C. Prácticas sociales y representaciones. México: Ed. Coyoacán, 2001.

AMOSSY, Ruth. L'argumentationdans le discours. Discours politique, literature d'idées, fiction. Paris: Nathan, 2000.

ANDERSON, Benedict. Comunidades imaginadas. Caracas: Fondo de Cultura Económica, 1983.

ANGENOT, Marc. La parolepamphlétaire. Paris: Payot, 1982.

ARISTÓTELES. El arte de la retórica. Buenos Aires: Eudeba, 2005.

ARNOUX, E.N. de. El discurso latinoamericanista de Hugo Chávez. Buenos Aires: Editorial Biblos, 2008a.

Los discursos sobre la nación y el lenguaje en la formación del Estado (Chile, 1842-1862): Estudio glotopolítico. Buenos Aires: Santiago Arcos editor, 2008b.

Análisis del discurso. Modos de abordar materiales de archivo. Buenos Aires: Santiago Arcos, 2006.

BARTHES, Roland. La retórica antigua. Prontuario. En: La aventura semiológica. Buenos Aires: Paidós, 1997.

CHARAUDEAU, P. La argumentación persuasiva. El ejemplo del discurso político. En: SHIRO, M. et. al. Haciendo discurso. Homenaje a Adriana Bolívar. Facultad de Humanidades y Educación, Universidad Central de Venezuela, Caracas, 2009.

GARCÍA DELGADO, D. Estado-nación y globalización. Buenos Aires: Ariel, 1998.

GARCÍA NEGRONI, María Marta. Negación y descalificación: a propósito de la negación metalingüística. Ciências \& Letras, n .45, Porto Alegre, pp. 61-8, 2009.

KERBRAT-ORECCHIONI, Catherine. L’énonciation. París: Armand Colin, 2006.

LÓPEZ, Damián. La cuestión nacional según Otto Bauer. Notas críticas en torno a un clásico. Estudios sociales: revista universitaria semestral, año XXI, nº. 41, Santa Fe, Argentina, Universidad Nacional del Litoral, pp. 9-40, 2011.

MAINGUENEAU, D. Las modalidades. En Introducción a los métodos del Análisis del Discurso: Problemas y perspectivas. Buenos Aires: Hachette, 1980.

MARTÍ, José. Nuestra América. Edición crítica. La Habana: Centro de Estudios Martianos, 1981.

VERÓN, Eliseo. La palabra adversativa. Observaciones sobre la enunciación política. En: El discurso político. Lenguajes y acontecimientos. Buenos Aires: Hachette, 1987. 
Artigo recebido em: setembro de 2016.

Aprovado e revisado em: dezembro de 2016.

Publicado em: abril de 2017.

\section{Para citar este texto:}

BUISÁN, Andres; SALERNO, Paula. Representaciones sobre el proceso de integración regional en los discursos de los líderes políticos del MERCOSUR. Entremeios [Revista de Estudos do Discurso, on-line], Seção Estudos, Programa de Pós-Graduação em Ciências da Linguagem (PPGCL), Universidade do Vale do Sapucaí (UNIVÁS), Pouso Alegre (MG), vol. 14, p. 3-22, jan. - jun. 2017.

DOI: http://dx.doi.org/10.20337/ISSN2179-3514revistaENTREMEIOSvol14pagina3a22 